\title{
THE CANNABIS CROP
}

Cannabis is one of humanity's oldest cultivated crops. But despite its long history and many uses, hard facts on its evolution and impact on the human body are in short supply. By Julie Gould.

\section{WHAT IS WEED?}

Various strains of cannabis exist, but there is no consensus on taxonomy. Sativa, indica and ruderalis might be three separate species or subspecies of Cannabis sativa.
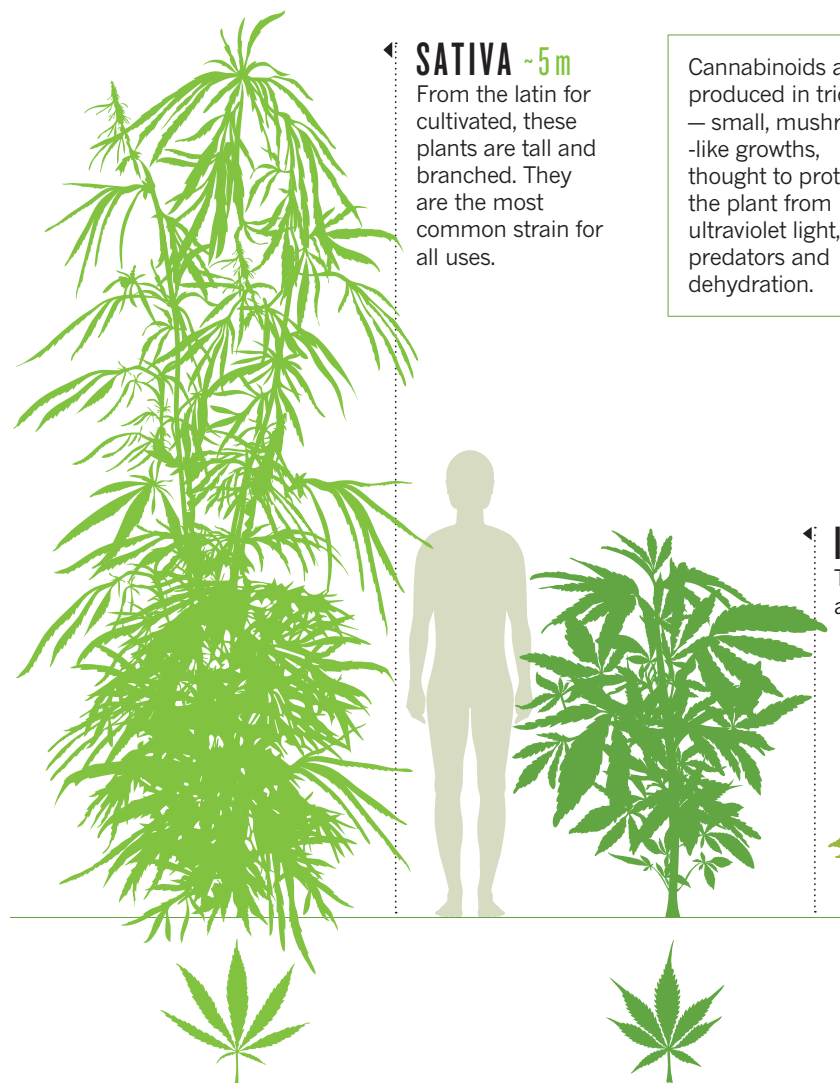

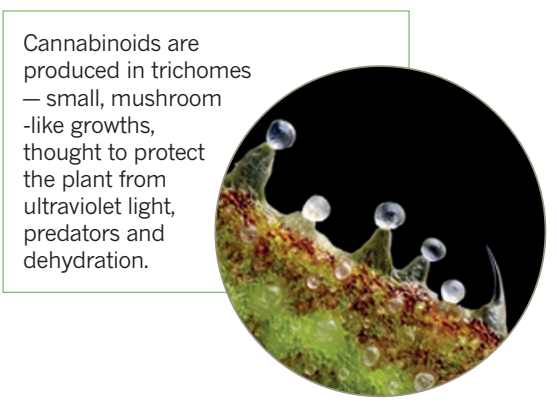

INDICA $1-2 \mathrm{~m}$

These short, broad-leaved plants are often used to make hashish.
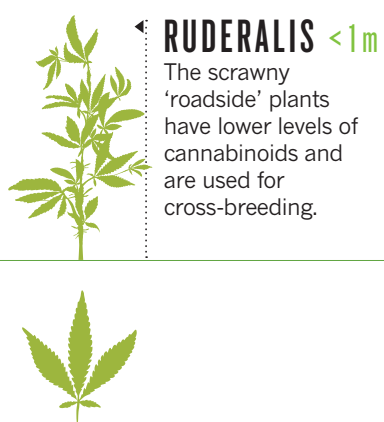

\section{DIVERSE USES}

Cannabis plants grown for fibre or hemp oil will differ in chemical make-up from those grown for medicinal or recreational use.

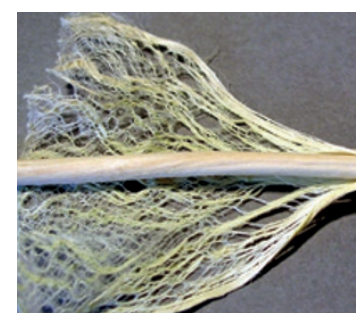

Material

The outer layer of the plant

consists of long bast fibres, which can be used to make fabrics.

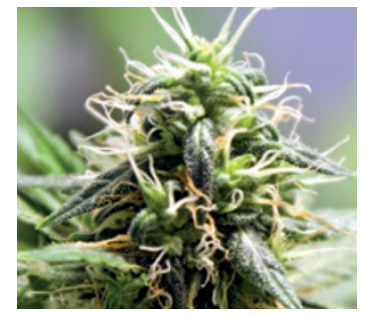

Medicine and intoxicants Trichomes on leaves and buds (pictured) produce the plant's medically usefu substances.

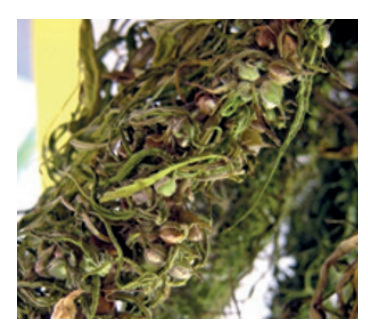

Food and cosmetics Hemp seeds are technically nuts and contain more than $30 \%$ oil and $25 \%$ protein.

\section{CHEMICAL CONSTIIUENTS}

Tetrahydrocannabinol (THC) is responsible for the mental high that can result from using cannabis. But there are many other cannabinoids and chemicals found in the plant, the roles of which are as yet unknown.

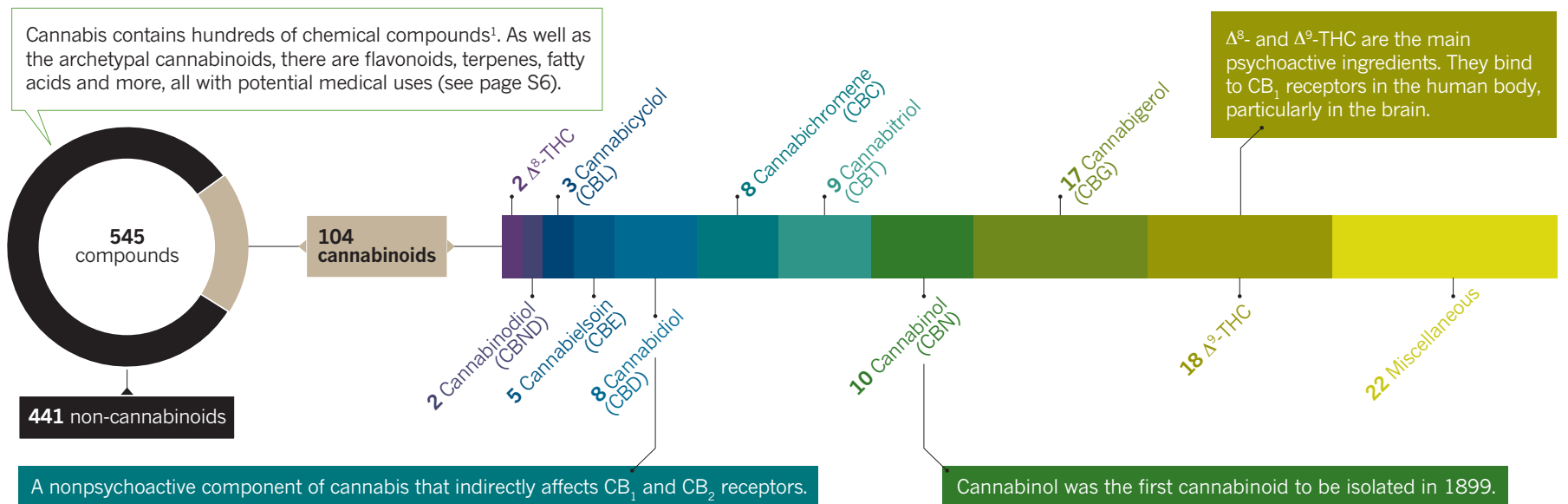


THE RESEARCH LANDSCAPE

The legal status of cannabis worldwide is in flux. One country and several US states have made herbal cannabis fully legal. Four countries have formal federal research programmes. Elsewhere, many countries have special exemptions for prescribed medical cannabis; others have decriminalized possession (not shown). Outside Europe and North America, however, severe punishments for even minor offences are common.

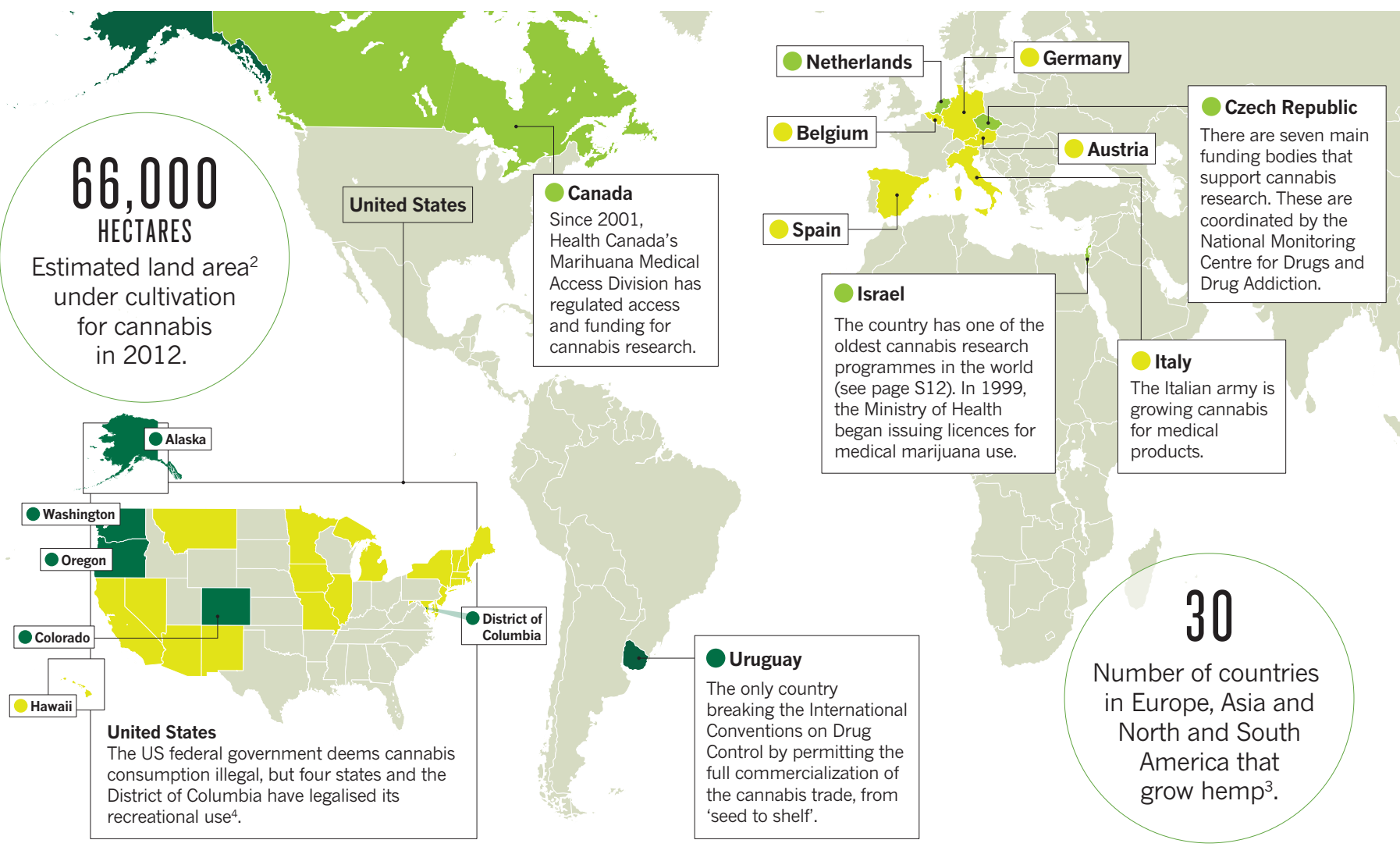

\section{PHYSIOLOGICAL PROCESSES}

The body's endocannabinoid system was discovered in 1988 as a result of THC research. So far, only two receptors have been studied in detail, although more have been found. Despite what the name suggests, there is not an exclusive relationship between cannabinoids and the endocannabinoid system: phytocannabinoids target a range of receptors.

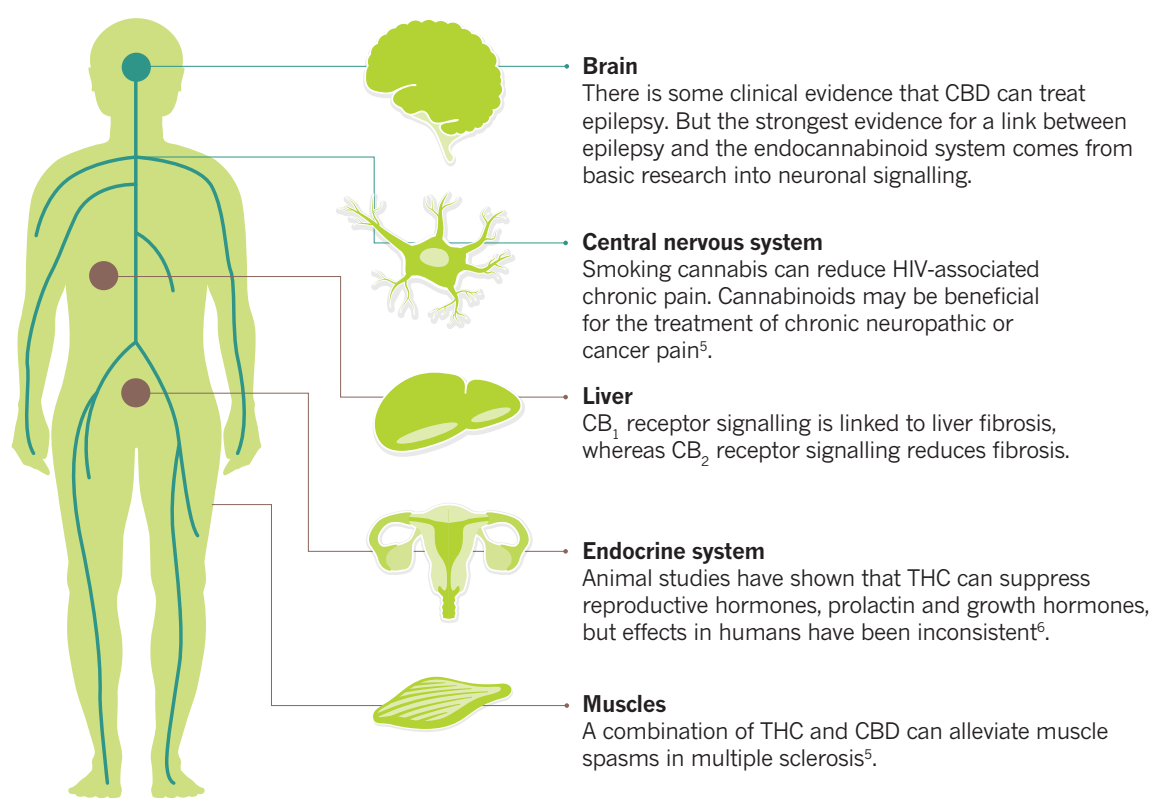

There is some clinical evidence that CBD can treat epilepsy. But the strongest evidence for a link between epilepsy and the endocannabinoid system comes from Central nervous system

Smoking cannabis can reduce HIV-associated chronic pain. Cannabinoids may be beneficia for the treatment of chronic neuropathic or Liver

$\mathrm{CB}_{1}$ receptor signalling is linked to liver fibrosis, whereas $\mathrm{CB}_{2}$ receptor signalling reduces fibrosis.

$\mathrm{CB}_{1}$ $\mathrm{CB}_{2}$

The two best known cannabinoid receptors are: $\mathrm{CB}_{1}$, which is mostly found in the central nervous system and to a lesser extent in peripheral nerves, the uterus, testes, bones and other body tissues; and $\mathrm{CB}_{2}$, which exists mostly in the immune system. 